Article

\title{
Impact of International Oil Price on Energy Conservation and Emission Reduction in China
}

\author{
Jian Chai ${ }^{1,2,3}$, Youhong Zhou ${ }^{2, *}$, Ting Liang ${ }^{2}$, Limin Xing ${ }^{2}$ and Kin Keung Lai ${ }^{4}$ \\ 1 School of Economics \& Management, Xidian University, Xi'an 710126, China; chaijian0376@126.com \\ 2 International Business School, Shaanxi Normal University, Xi'an 710119, China; \\ liangting07031992@163.com (T.L.); xinglm0219@163.com (L.X.) \\ 3 Academy of Mathematics and Systems Science, Chinese Academy of Sciences, Beijing 100190, China \\ 4 Department of Management Sciences, City University of Hong Kong, Hong Kong; mskklai@cityu.edu.hk \\ * Correspondence: zhou9309@126.com; Tel.: +86-29-8531-0297
}

Academic Editor: Andrew Kusiak

Received: 11 April 2016; Accepted: 18 May 2016; Published: 26 May 2016

\begin{abstract}
In the context of "new normal" economy and frequent "haze", the strategy of energy conservation and emission reduction aiming to lower costs and reduce pollution is currently still a major strategic direction in China and the world, and will remain so for some time in the future. This paper uses the annual data of West Texas Intermediate (WTI) crude oil price in 1987-2014 as samples. We firstly present the direction and mechanism of the influence of oil price change on total consumption of every kind of energy by path analysis, and then consider establishing a Structural Vector Autoregression model of energy conservation and emission reduction in three statuses. Research shows that if the international oil price increases by $1 \%$, the energy consumption per GDP and carbon dioxide emission increase by $0.092 \%$ and $0.053 \%$ respectively in the corresponding period. In the status of high energy consumption and high emission, if the international oil price increases by $1 \%$, the energy consumption per GDP and carbon dioxide emission increase by $0.043 \%$ and $0.065 \%$ respectively in the corresponding period. In the status of low energy consumption and low emission, if the international oil price increases by $1 \%$, the energy consumption per GDP per unit increases by $0.067 \%$ and carbon dioxide emission decreases by $0.085 \%$ in the corresponding period.
\end{abstract}

Keywords: WTI crude oil price; energy conservation and emission reduction; path analysis; SVAR model

\section{Introduction}

Climatic change is a common challenge that is faced by mankind nowadays, and haze has had a strong impact on people's lives. In 2014, the average number of haze days in China was 35.9 which was the largest since 1961. The increasing aggravation of environmental pollution has become a series challenge for China to realize its goals of energy conservation and emission reduction. The carbon dioxide emission increased from 2172.13 million tons in 1987 to 9761.08 million tons in 2014, an increase of $78 \%$. The sulfur dioxide emission increased from 13.23 million tons in 1992 to 18.64 million tons in 2014, an increase of $40.8 \%$. Meanwhile, the continuous increase of energy consumption has put an enormous pressure on China to save energy and reduce emission. The energy consumption in China increased from 8663.20 billion tons of standard coal in 1988 to $42,600.00$ billion tons of standard coal in 2014, a 23.95-fold increase. Meanwhile, in the corresponding period, the West Texas Intermediate (WTI) crude oil price increased from 19.14 dollars/barrel in 1994 to 93.28 dollars/barrel, and reached its peak value of 100.06 dollars/barrel in 2008. Due to the substitutability of energy, the fluctuation of oil price has a strong impact on economic security, energy consumption and environment quality. The reasonable analysis on the impact of crude oil price change on energy consumption as well 
as energy conservation and emission reduction is of important reference significance for China to maintain the sustainable increase of economy and establish the policy of energy conservation and emission reduction.

The research on the impact effect of international oil price on economic development has drawn a lot of domestic and international scholars' attention. (Hamilton [1,2], Kilian [3,4], Hooker [4], and Alvarez [5] et al.) However, there are few research papers on the impact of oil price on energy consumption and emission reduction in China. He Lingyun [6] et al. have analyzed the lever effect of relative energy price in China on the price of carbon emission by establishing: a univariate model, a model of a group of variables, and a simultaneous equations model. They come to the conclusion that when the combined action of economic aggregate, industrial structure, and energy efficiency is considered, the stimulation effect of the whole group of variables on carbon emission significantly reduces while the effect of energy price leverage on carbon emission reduction significantly increases. Based on supply-demand theory, Liu Chang [7] established an energy-economy simultaneous equations model to analyze the influence of energy price change on macroeconomy as well as energy conservation and emission reduction in China. The research shows that the increase of energy price can lower energy consumption, which has a tightening effect on potential production capacity through supply channels. The negative influence of a continuous increase of all kinds of energy price on potential production output, energy consumption, energy intensity and carbon emission intensity tends to continuously increase.

A lot of scholars have undertaken research into the negative influence of energy price leverage and energy price change on carbon emission and energy intensity, but they should analyze more deeply the impact of energy price change on energy consumption as well as emission reduction [8-11]. Foreign scholars have applied innovative research methods related to energy price. Kilian et al. (2014) [12] applied the improved economic growth model to analyze the impact of oil price on the American economy, and drew the conclusion that from the end of the 1970s to the beginning of the 1980s, due to the impact of oil price, the real GDP in America accumulatively reduced by 3\%, and it accumulatively reduced by $5 \%$ during the period of financial crisis. Canova J et al. (2014) [13] applied the revenue and expenditure balance model to estimate the economic trade balance and balance of international payment structure in Mexico, and the results showed that the relatively strong restraint on balance of international payment had a negative influence on the economy in Mexico, and the effective exchange rate caused a decrease of trade balance, and increased the export industry to integrate into global supply chain.

With the development of economy, industrialization and informationization have improved, and urbanization level has been further enhanced; thus, the energy consumption pattern and growth speed will correspondingly change. As the demand on energy always maintains the tendency of a strong increase, as a strategic resource as well as a financial product, the price of oil will certainly be impacted by many comprehensive factors [14-16]. On the one hand, the marketization degree of the price of oil and coal has been very high in China, and was basically geared to international standards. The rise of the international oil price will directly result in the rise of oil and natural gas price in China as well as a price rise for products such as coal, water and electricity, etc. On the other hand, with the continuous development of economic level, the incidence of car ownership is continuously increasing, and the number of plants is continuously increasing, so the consumption of primary energy such as oil causes the aggravation of environmental pollution. The research on the impact effect of international oil price on energy conservation and emission reduction in China is of important practical significance, but there are few researches on this aspect in China. In view of this, the paper plans to start from an analysis of the influence mechanism of international oil price on primary energy consumption structure in China to analyze the impact effect of international crude oil price change on energy conservation and emission reduction in China.

The basic structure of this paper is as follows: 1. Introduction, the background and theoretical significance of the research subject in this paper; 2. Data Source and Handling, (1) Classification 
of Energy Conservation and Emission Reduction Effect Status; 3. Model Building; (1) Influence Path Analysis of International Oil Price on Energy Consumption in China; (2) Structural Vector Autoregression Model Analysis of impulse impact between Energy Conservation and Emission Reduction in China between International Oil Price; 4. Conclusion.

\section{Date Source and Handling}

The fluctuation of international oil price influences energy consumption through the exchange rate and gross domestic product. Influenced by the policy of energy conservation and emission reduction in China, on the one hand, the fluctuation of international crude oil price directly influences the efficiency of energy conservation and emission reduction in China. On the other hand, it indirectly influences the energy conservation and emission reduction in China through energy consumption and change of consumption structure. Based on this, the paper plans to select coal, oil, natural gas, water and electricity consumption, exchange rate, carbon dioxide emission, and gross domestic product as variables to be surveyed.

This paper firstly makes logarithm processing on every indicator to remove heteroscedasticity, and divides the primary energy in China into coal, oil, natural gas and water and electricity. The annual data of West Texas Intermediate (WTI) spot crude oil in 1987-2014 (data source: EIA [17]), the data of total coal, oil, natural gas, and water and electricity consumption in 1987-2014 (data source: China Statistical Yearbook [18]), the closing exchange rate (data source: Royal Flush Database [19]) and GDP (data source: Royal Flush Database [19]) in 1987-2014 reflect the situation of economic growth. The data of carbon dioxide emission and energy consumption per GDP in 1987-2014 (data source: Royal Flush Database [19]) reflect the energy conservation and emission reduction effect indicators.

\section{Classification of Energy Conservation and Emission Reduction Effect Status}

The influence of the factors such as policy, environment, and economy on energy conservation and emission reduction is different in different periods. This paper selects carbon dioxide emission and energy consumption per GDP as indicators to be surveyed to classify the status of energy conservation and emission reduction effect. The significant increase or decrease of energy conservation and emission reduction effect can be regarded as the status switching of the influential factors such as policy, environment, and economy on energy conservation and emission reduction from increase/decrease to decrease/increase. The carbon dioxide emissions and per GDP energy consumption decrease/increase is defined as the 0 status. The amount of carbon dioxide emissions, and per GDP energy consumption increase/decrease is defined as the 1 status. When increasing, carbon dioxide emissions and per unit GDP energy consumption is relatively less in low pollution and low emission levels; when in decline, carbon dioxide emissions and energy consumption per GDP actually larger in high pollution and high emissions levels. In Markov switching model, such mechanism switching is regarded as an endogenous variable. The mechanism switching is assumed as random, and a model is used to measure the structure change. The Markov mechanism switching method is to divide the events which may happen into $n$ statuses to show the mechanism in $n$ statuses. Based on Hamilton's (1898) Markov mechanism switching model, the paper establishes the Markov mechanism switching model in two statuses after screening according to AIC and SC information criteria. Among them, the MS(2)-AR(2) model of carbon dioxide emission (Model 1) and energy consumption per GDP (Model 2) are shown as follows:

$$
\begin{aligned}
& D C O 2_{t}=U D C O 2_{t}+\alpha_{t} D C O 2_{t-1}+\beta_{t} D C O 2_{t-2}+\varepsilon_{t} \\
& P G D P_{t}=U P G D P_{t}+\alpha_{t}^{\prime} P G D P_{t-1}+\beta_{t}^{\prime} P G D P_{t-2}+\varepsilon_{t}
\end{aligned}
$$

This gives the serial mean of carbon dioxide emission at the time of $t$ : in a different status, the mean value is different; PGDP represents energy consumption per GDP, UPGDP is the serial mean of energy consumption per GDP, and in a different status, the mean value is different; $\alpha_{t}, \beta_{t}, \alpha^{\prime}$ and $\beta_{t}^{\prime}$ represent autoregressive coefficients at the time of $\mathrm{t}$, and $\varepsilon$ represents error term. 
In this paper, the data of carbon dioxide emission and energy consumption per GDP in 1988-2014 is selected and EVIEWS 8.0 (http:/ / www.eviews.com/home.html, IHS Global Inc, Irvine, CA, USA) is applied to calculate the smoothing probabilities in the two statuses which are shown in Figures 1 and 2. As defined, a smoothing probability larger than 0.5 is a positive influence while values of less than 0.5 represent negative influence. The positive influence is defined as 1 , and the negative influence is defined as 0 . We respectively classify the status of carbon dioxide emission and energy consumption per GDP to establish the $d c o 2$ time series of carbon dioxide emission and the p $g d p$ dummy variable of energy consumption per GDP. As can be seen from Figure 1a, the per GDP energy consumption regime 1 (a smooth probability for most cases in the 0 status) is defined as the state of low energy consumption. Figure $1 \mathrm{~b}$ energy consumption per GDP, regime 2 (a smooth probability in most of the 1 status cases), is defined as high energy consumption status. As can be seen from Figure 2a, for the carbon dioxide emissions, regime 1 (a smooth probability of most cases in the 0 state), is defined as a low emission state. Figure $2 b$ the carbon dioxide emissions in regime 2 (a smooth probability of most cases in the 1 status), is defined as a high emission state.

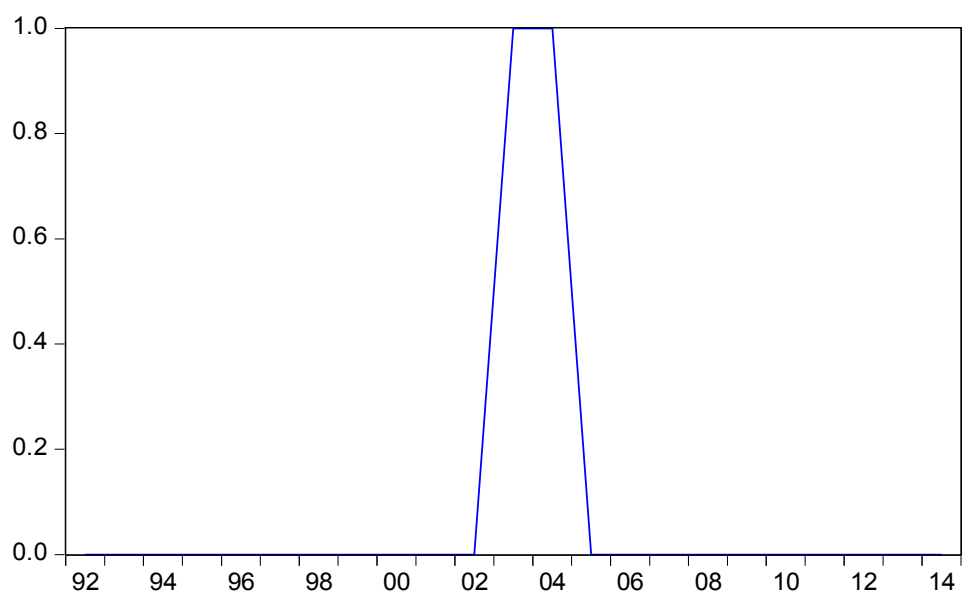

(a)

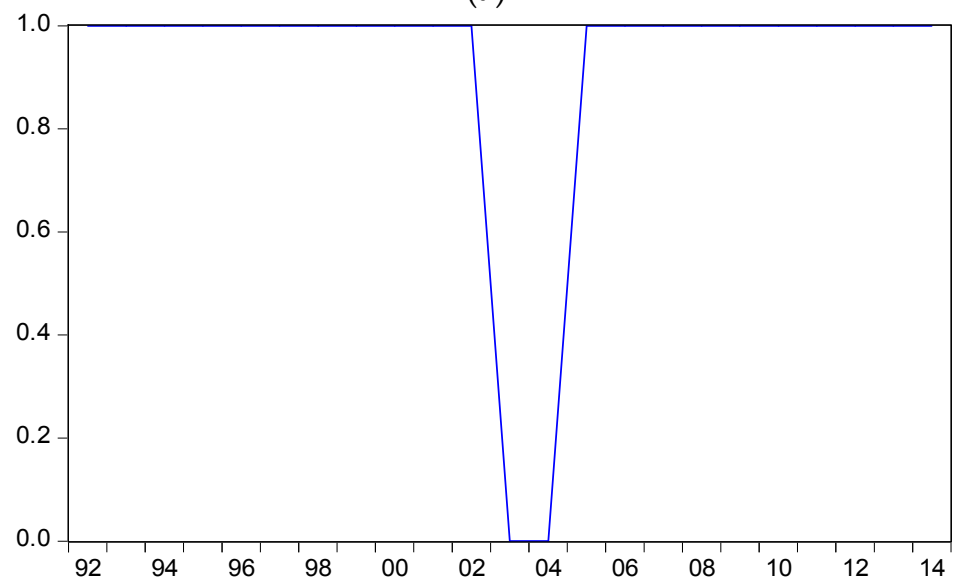

(b)

Figure 1. Smoothed Regime Probabilities for PGDP in two statuses. They should be listed as: (a) Smoothed Regime Probabilities for which $\mathrm{P}(\mathrm{S}(\mathrm{t})=1)$ is contained in the first panel; (b) Smoothed Regime Probabilities for which $\mathrm{P}(\mathrm{S}(\mathrm{t})=2)$ is contained in the second panel. 


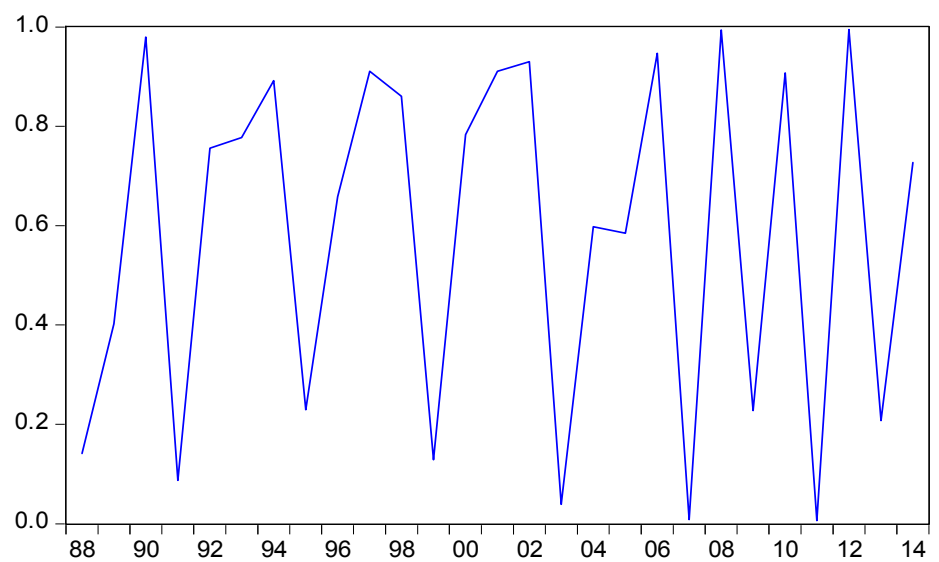

(a)

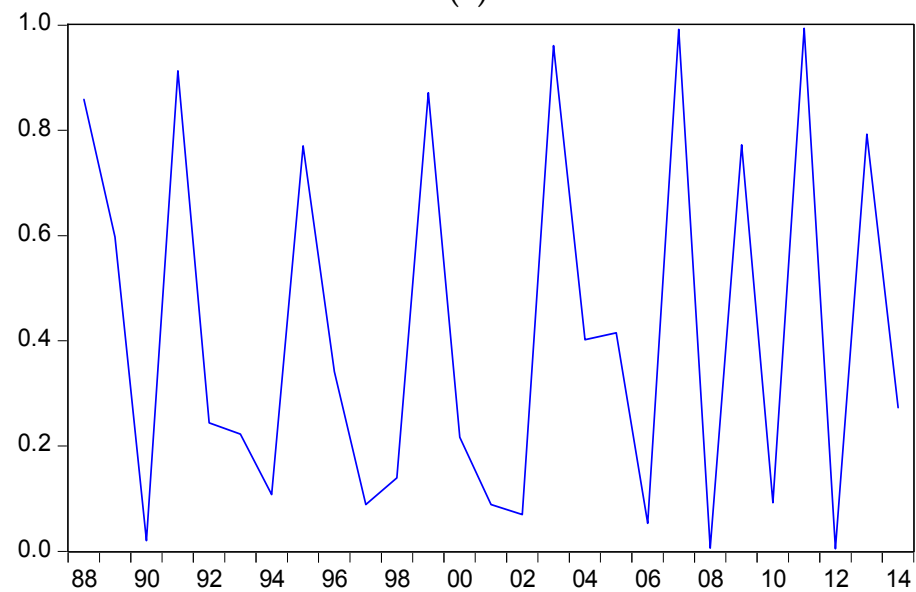

(b)

Figure 2. Smoothed Regime Probabilities for DCO2 in two statuses. They should be listed as: (a) Smoothed Regime Probabilities for which $\mathrm{P}(\mathrm{S}(\mathrm{t})=1)$ is contained in the first panel; (b) Smoothed Regime Probabilities for which $\mathrm{P}(\mathrm{S}(\mathrm{t})=2)$ is contained in the second panel.

\section{Empirical Analysis}

\subsection{Influence Path Analysis of International Oil Price on Energy Consumption in China}

Consumption affects the status of economic development and enhances the increase of energy supply. Due to economic globalization, the marketization of energy price has been continuously strengthened, the energy price in China has been basically geared to the international level, and the dependency between economic entities has been very high. The rise of international oil price has not only caused a rise of oil and natural gas prices in China, but also leads to a rise in the price coal, etc. The fluctuation of international energy prices, the change of exchange rates, and the status of economic development are significant variables effecting energy consumption, and there is relatively strong dependency and recursion among energy consumption, exchange rate, and gross domestic product. In this paper, WTI crude oil price is selected as an international oil price to analyze the influence of the fluctuation of international oil prices on the economic and energy consumption structure in China.

On the one hand, with economic development, the total energy consumption is increased, but due to the substitutability of energy use, the international oil price directly influences the total raw coal consumption, the total crude oil consumption, the total natural gas consumption and the total water and electricity consumption in China. On the other hand, we based our work on a lot of scholarly research on the influence of international oil prices on the macroeconomy in China [20-26], analyzing the indirect influence of international oil prices on the energy consumption structure in 
China. As China entered the WTO, the economic development in China has been gradually geared to the international level, and the international oil price influences the total energy consumption and its consumption structure through exchange rates. During the fluctuation of exchange rates, the international oil price also indirectly influences the consumption of all kinds of energy through gross domestic product. The influence path diagram is shown as Figure 3.

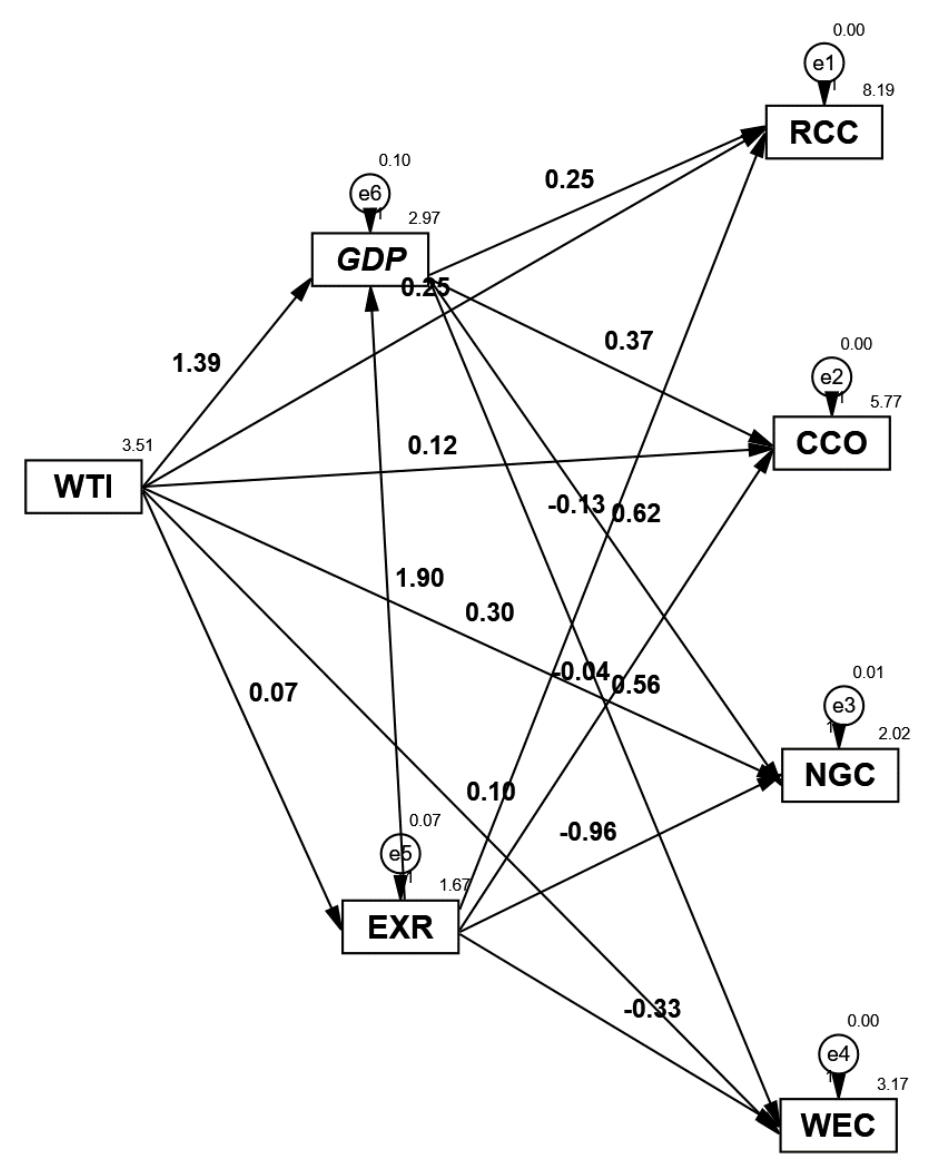

Figure 3. International oil price and energy consumption path diagram.

Path Analysis Model of Energy Consumption in China Based on International Oil Price

Since path analysis was put forward by the geneticist, Wright (1918-1921), it has become an important method of multivariate analysis, and it has been widely applied to analyze the causal relationship among variables in the fields of genetics, sociology, psychology, economic issues, and market surveys [27]. In this paper, a multivariate dynamic regression model is established based on the path diagram of Figure 3, as shown in Model (3).

$$
\begin{aligned}
& E X R=\alpha_{1} W T I+\varepsilon_{5} \\
& G D P=\alpha_{2} W T I+\beta_{2} E X R+\varepsilon_{6} \\
& C C O=\alpha_{3} W T I+\beta_{3} E X R+\delta_{3} G D P+\varepsilon_{2} \\
& R C C=\alpha_{4} W T I+\beta_{4} E X R+\delta_{4} G D P+\varepsilon_{1} \\
& N G C=\alpha_{5} W T I+\beta_{5} E X R+\delta_{5} G D P+\varepsilon_{3} \\
& W E C=\alpha_{6} W T I+\beta_{6} E X R+\delta_{6} G D P+\varepsilon_{4}
\end{aligned}
$$

Among them, WTI represents the WTI crude oil price in America, EXR is defined as the exchange rate of RMB to USD, RCC is the total consumption of crude oil, NGC is the total consumption of natural gas, and WEC is the total consumption of water and electricity. $\varepsilon_{i}, \mathrm{i} \in 1,2,3 \cdots 6$. is the residual error. 
In this paper, AMOS 21.0 (http://www-01.ibm.com/software/cn/analytics/spss/downloads.html, IBM, Armonk, New York city, NY, USA) is applied to realize the path analysis of energy consumption in China based on international oil price. The direct influence of international oil price on energy consumption structure in China can be observed from Figure 3 and Table 1: as we all know, the energy consumption in China is dominated by coal, and coal mining is seriously affected by the fluctuation of international oil price. Moreover, the elasticity of international oil prices in relation to the total consumption of raw coal in China is 0.385 . The exploration of crude oil and natural gas tend to be centralized, so the influence of international oil price is basically balanced, and the elasticity in relation to the total consumption of crude oil in China is 0.153 , while the elasticity in relation to the total consumption of natural gas is 0.243 . Fields such as water and electricity utilization are limited by this, so the influence of international oil price on water and electricity consumption is relatively weak, and the elasticity in relation to the total consumption of water and electricity in China is 0.096 .

Table 1. Path analysis of energy consumption in China based on international oil price.

\begin{tabular}{cccc}
\hline & & & Estimate \\
\hline EXR & $\leftarrow$ & WTI & 0.168 \\
GDP & $\leftarrow$ & WTI & 0.787 \\
GDP & $\leftarrow$ & EXR & 0.436 \\
CCO & $\leftarrow$ & EXR & -0.020 \\
RCC & $\leftarrow$ & WTI & 0.385 \\
NGC & $\leftarrow$ & WTI & 0.243 \\
WEC & $\leftarrow$ & WTI & 0.096 \\
RCC & $\leftarrow$ & EXR & -0.078 \\
NGC & $\leftarrow$ & EXR & -0.317 \\
WEC & $\leftarrow$ & EXR & -0.134 \\
RCC & $\leftarrow$ & GDP & 0.673 \\
CCO & $\leftarrow$ & GDP & 0.870 \\
NGC & $\leftarrow$ & GDP & 0.898 \\
CCO & $\leftarrow$ & WTI & 0.153 \\
WEC & $\leftarrow$ & GDP & 0.979 \\
\hline
\end{tabular}

The indirect influence of international oil price on energy consumption structure in China can be described as follows. First, the international oil price influences energy consumption structure in China through macroeconomy in China. Because of the gradual development of the economy in China, the macroeconomy in China is strongly impacted by international oil price, and the influence of WTI crude oil on gross domestic product is 0.787 . Energy has the power to enhance economic development, and raw coal, crude oil, natural gas, and water and electricity are strongly affected by the Chinese economy. The elasticity of the gross domestic product in relation to the total consumption of raw coal in China is 0.673 , the elasticity in relation to the total consumption of crude oil in China is 0.870 , the elasticity in relation to the total consumption of natural gas in China is 0.898 , and the elasticity in relation to the total consumption of water and electricity in China is 0.979 . Second, the international oil price influences energy consumption in China through the exchange rate. The exchange rate is comprehensively influenced by the economy of two countries, so the direct influence of international oil price on the exchange rate is not strong, and the influence of WTI crude oil on the exchange rate is 0.168. In addition, the influence of exchange rate on energy consumption in China is relatively weak. The elasticity of exchange rate in relation to the total consumption of raw coal in China is -0.078 , the elasticity in relation to the total consumption of crude oil in China is -0.02 , the elasticity in relation to the total consumption of natural gas in China is -0.317 , and the elasticity in relation to the total consumption of water and electricity in China is -0.134 . Therefore, the influence of international oil price on energy in China through the exchange rate is very small. Third, under the premise of the exchange rate, the international oil price influences energy consumption in China through the macro economy in China. As the Chinese economy develops rapidly, the influence of exchange rate 
on gross domestic product is 0.436 , and the macro economy in China has strong influence on energy consumption. In this way, under the premise of exchange rate, the international oil price has certain influence on energy consumption in China through the macroeconomy in China.

\subsection{Dynamic Influence Effect Analysis of International Oil Price on Energy Consumption and Emission Reduction in China}

In the influence path analysis model of international oil price on energy consumption in China, the influence of international oil price on energy consumption in China is preliminarily described. The effect of the influence of international oil price on energy conservation and emission reduction in China needs to be further analyzed. Firstly, due to economic development and excessive energy consumption, a lot of dust, solid particulates, sulfides, and nitrides are put pressure on energy conservation and emission reduction. Based on the analysis of the influence of international oil price on energy consumption in China, this paper analyzes the relations between macroeconomy, energy consumption, and emission reduction effect in China. Secondly, Markov switching is applied to divide the statuses of energy consumption per GDP and carbon dioxide emission time series, and research the impact effect of international oil price on energy consumption and emission reduction in China by discussing the influence of international oil price in the status of serious energy consumption and environmental pollution as well as the status of relatively weak energy consumption and environmental pollution.

\subsubsection{Structure Vector Autoregression Model of Energy Conservation and Emission Reduction in} China Based on International Oil Price

Since the VAR model was introduced into economics by Sims (1980), it has enhanced the wide application of economic system dynamics analysis, but no definite form of current relations between variables is given in the VAR model. Scholars have continuously improved the VAR model, and Kilian [12] (2014) optimized the VAR model to analyze the impact of international oil price on economic recession. With reference to the economic growth model, this paper selects the logarithmic growth percentage of the original value and puts forward a dynamic model of the influence of international oil price on consumption in China.

Because there are identification conditions in the SVAR model, there are five variables in this paper. For the short-term relation matrix, at least 10 limits are required to guarantee the identification of the equation, and 11 limits are set in the model applied in this paper. Assume: (1) international crude oil price is an exogenous factor in current period, and it is not influenced by energy consumption per GDP, carbon dioxide emission, total energy consumption in China, and gross domestic product in China; (2) energy consumption per GDP and carbon dioxide emission are not influenced by each other; (3) energy consumption per GDP and carbon dioxide emission have no influence on total energy consumption and gross domestic product in China; (4) Total energy consumption in China has no influence on gross domestic product in China. Moreover, the vector autogression model of international oil price on energy conservation and emission reduction in China is established, as shown in Model (4).

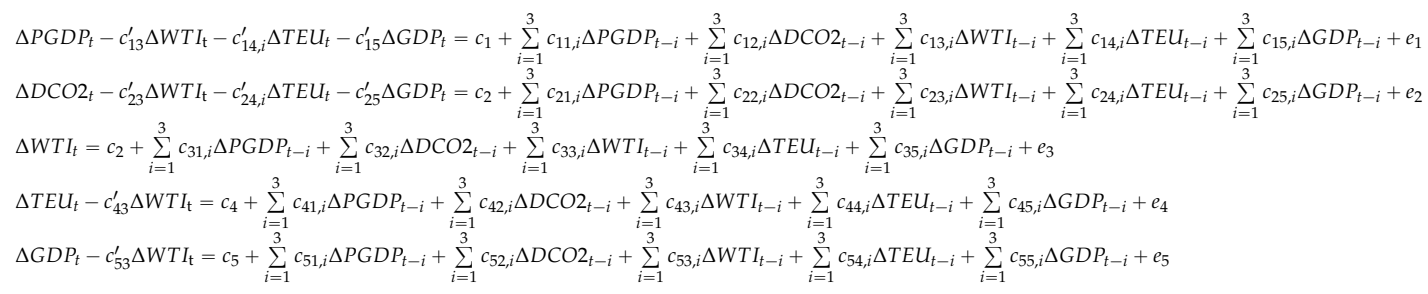

PGDP is the energy consumption per GDP, DCO2 is the carbon dioxide emission, WTI crude oil represents WTI crude oil price (through path analysis, the exchange rate has a certain impact on China's energy consumption, the structure of the vector from the back to the model, the international price of crude oil to the product of interest rates and WTI crude oil prices), TEU is the total energy consumption 
in China, GDP is the gross domestic product, $i$ is the number of lag phase, and $e$ represents error term. Model (4) is simply converted to be shown as

$$
A Y=C+\sum_{i=1}^{3} \Gamma_{i} Y_{\mathrm{t}-i}+\mathrm{E}
$$

In Model (5),

$$
Y=\left(\begin{array}{c}
\Delta P G D P \\
\Delta D C O 2 \\
\Delta W T I \\
\Delta T E U \\
\Delta G D P
\end{array}\right), C=\left(\begin{array}{c}
c_{1} \\
c_{2} \\
c_{3} \\
c_{4} \\
c_{5}
\end{array}\right), A=\left(\begin{array}{ccccc}
1 & 0 & -c_{13}^{\prime} & -c_{14}^{\prime} & -c_{15}^{\prime} \\
0 & 1 & -c_{23}^{\prime} & -c_{24}^{\prime} & -c_{25}^{\prime} \\
0 & 0 & 1 & 0 & 0 \\
0 & 0 & -c_{43}^{\prime} & 1 & -c_{45}^{\prime} \\
0 & 0 & -c_{53}^{\prime} & 0 & 1
\end{array}\right), \Gamma_{i}=\left(\begin{array}{cccc}
c_{11}^{(i)} & c_{12}^{(i)} & \ldots & c_{15}^{(i)} \\
c_{21}^{(i)} & c_{22}^{(i)} & \ldots & c_{25}^{(i)} \\
\vdots & \vdots & \vdots & \vdots \\
c_{51}^{(i)} & c_{52}^{(i)} & \ldots & c_{55}^{(i)}
\end{array}\right), \mathrm{E}=\left(\begin{array}{c}
e_{1} \\
e_{2} \\
\vdots \\
e_{5}
\end{array}\right)
$$

All variables selected lag six phases, and according to the lowest value criteria of AIC and SC, the number of lag phases of variables is determined as three phases. In the model test, the reciprocals of characteristic polynomials in the vector autoregression model of international oil price on energy conservation and emission reduction in China are all less than 1, and within the unit circle, which indicates that the model of economic growth is stable.

\subsubsection{SVAR Model of Energy Conservation and Emission Reduction in China in Different Statuses Based on International Oil Price}

Based on SVAR model analysis, it is concluded that the international oil price has certain influence on energy conservation and emission reduction in China, but the degree of severity of energy consumption and environmental pollution cannot be separated. In this paper, the Markov switching method is applied to divide the energy consumption per GDP and the carbon dioxide emission into two statuses, high energy consumption and high emission as well as low energy consumption and low emission, to further analyze the influential effect of international oil price on energy conservation and emission reduction in China in different statuses. Based on model (5), the vector autoregression model of energy conservation and emission reduction in China in different statuses based on international oil price is established.

$$
\begin{aligned}
& A Y_{1}=C+\sum_{i=1}^{3} \Gamma_{i} Y_{\mathrm{t}-i}+\mathrm{E} \\
& A Y_{2}=C+\sum_{i=1}^{3} \Gamma_{i} Y_{\mathrm{t}-i}+\mathrm{E}
\end{aligned}
$$

In Models (6) and (7),

$$
Y_{1}=\left(\begin{array}{c}
\triangle P G D P_{2} \\
\triangle D C O 2_{1} \\
\Delta W T I \\
\Delta T E U \\
\triangle G D P
\end{array}\right), Y_{2}=\left(\begin{array}{c}
\triangle P G D P_{1} \\
\triangle D C O 2_{2} \\
\Delta W T I \\
\Delta T E U \\
\Delta G D P
\end{array}\right)
$$

In the equation above, $P G D P_{2}$ represents energy consumption series per GDP in the status of high energy consumption, $P G D P_{1}$ is the energy consumption series per GDP in the status of low energy consumption, $D C O 2_{1}$ is the carbon dioxide emission series in the status of high emission, and $D C O 2_{2}$ is the carbon dioxide emission series in the status of low emission. The reciprocals of characteristic polynomials in the vector autoregression model of energy conservation and emission reduction in China based on international oil price on are all less than 1, and within the unit circle, which indicates that the model of economic growth is stable. 
3.2.3. SVAR Model Analysis of Energy Consumption and Emission Reduction in China between International Oil Price

Table 2 estimates the influence between the international crude oil price (WTI), total energy consumption in China (TEU), and gross domestic product in China (GDP), and the energy consumption per GDP (PGDP) and carbon dioxide emission (DCO2) in the same period without classification of status. In this paper, all estimated variables are the logarithmic difference of original variables, so the influence in the same period is presented as the marginal effect of the change rate of one variable to that of another.

Table 2. SVAR Model Result without Classification of Status.

\begin{tabular}{cccccc}
\hline Variable & PGDP & DCO2 & WTI & TEU & GDP \\
\hline PGDP & 1.000000 & 0.000000 & $0.092165^{*}$ & $-0.8948^{*}$ & $0.126460^{*}$ \\
& & & $(0.0000)$ & $(0.0000)$ & $(0.0000)$ \\
DCO2 & 0.000000 & 1.000000 & $0.050294^{* *}$ & $-0.5866^{*}$ & -0.0808 \\
& & & $(0.0481)$ & $(0.0003)$ & $(0.2532)$ \\
WTI & 0.000000 & 0.000000 & 1.000000 & 0.000000 & 0.000000 \\
TEU & 0.000000 & 0.000000 & -0.0263 & 1.000000 & $-0.2076^{*}$ \\
& & & $(0.4091)$ & $(0.0088)$ \\
GDP & 0.000000 & 0.000000 & -0.1242 & 0.000000 & 1.000000 \\
& & & \\
& & Log likelihood: 256.5103 & \\
\hline
\end{tabular}

Note: the value in brackets is $p$ value; ${ }^{*}$ represents $1 \%$ significance level; ${ }^{* *}$ represents $5 \%$ significance level; and *** represents $10 \%$ significance level.

The analysis results show that: in the aspect of energy conservation, the marginal influential effect of international crude oil price change rate on energy consumption per GDP is 0.092165 , and $p$ value is less than 0.05 , with statistical significance, which indicates that, in the short term, the rise and fall of international crude oil price will result in the change of energy consumption per GDP in China in the same direction, and the rise of international crude oil price will result in the increase of energy use efficiency, with the effect of energy conservation. In the aspect of environmental pollutant emission, the marginal influential effect of international crude oil price exchange rate on carbon dioxide emission is 0.050294 , and $p$ value is less than 0.05 , with statistical significance. Based on the explanation of dynamic views mentioned above, this indicates that the total energy consumption increases with a rise of international oil price in the current period, so the pollutant emission increases naturally, but the elasticity coefficient is different. Based on the above-mentioned results of measurement, when the crude oil price in the current period increases by $1 \%$, the carbon dioxide emission in current period will increase by $0.050294 \%$. The elasticity coefficient is lower than the elasticity coefficient of energy intensity to energy price change, which means that the speed of energy consumption increase is higher than the speed of pollutant emission. This indicates that the energy consumption structure in China has been continuously optimized, and the energy pollutant emission has been effectively controlled.

Table 3 estimates the influence between the international crude oil price (WTI), total energy consumption in China (TEU), and gross domestic product in China (GDP), and the energy consumption per GDP (PGDP) and carbon dioxide emission (DCO2) in the same period in the status of high energy consumption and high emission. 
Table 3. SVAR model result in the status of high energy consumption and high emission.

\begin{tabular}{cccccc}
\hline Variable & PGDP & DCO2 & WTI & TEU & GDP \\
\hline PGDP & 1.000000 & 0.000000 & $0.043085^{*}$ & $-0.2961^{*}$ & $-0.0364^{* *}$ \\
& & & $(0.0000)$ & $(0.0000)$ & $(0.0131)$ \\
DCO2 & 0.000000 & 1.000000 & $0.065117^{* *}$ & $-1.0724^{*}$ & $0.282057^{* *}$ \\
& & & $(0.0278)$ & $(0.0000)$ & $(0.0019)$ \\
WTI & 0.000000 & 0.000000 & 1.000000 & 0.000000 & 0.000000 \\
TEU & 0.000000 & 0.000000 & -0.0202 & 1.000000 & -0.1409 \\
& & & $(0.6659)$ & & $(0.3160)$ \\
GDP & 0.000000 & 0.000000 & $-0.1177^{* * *}$ & 0.000000 & 1.000000 \\
& & & $(0.0692)$ & &
\end{tabular}

Log likelihood: 245.4754

Note: the value in brackets is $p$ value; ${ }^{*}$ represents $1 \%$ significance level; ${ }^{* *}$ represents $5 \%$ significance level; and *** represents $10 \%$ significance level.

By comparison between Tables 2 and 3 in the aspect of energy conservation, it can be observed that all $p$ values are less than 0.05 , with statistical significance, and the influence of international oil price and gross domestic product in China on energy consumption per GDP reduces (from 0.092165 to 0.043085 , and from 0.126460 to -0.0364 respectively), which indicates that the high energy consumption is mainly from the non-oil energy at low cost. Meanwhile, the influence of total energy consumption in China on energy consumption per GDP increases (from -0.8948 to -0.2961 ), which indicates that the increase of energy consumption directly causes the increase of total energy supply, as well as the increase of energy consumption per GDP. In the aspect of pollutant emission, the direct influence of economic development on environmental pollution rapidly increases in short time (from -0.0808 to 0.282057 ), and the influence of international oil price and total energy consumption on energy consumption per GDP increases (from 0.050294 to 0.065117 , and from -0.5866 to -1.0724 respectively), which indicates that in the status of high emission, compared with the normal situation, the influence of energy consumption, economic development, and international oil price correspondingly increases.

Table 4 estimates the influence between the international crude oil price (WTI), total energy consumption in China (TEU), and gross domestic product in China (GDP), and the energy consumption per GDP (PGDP) and carbon dioxide emission (DCO2) in the same period in the status of low energy consumption and low emission.

Table 4. SVAR model result in the status of low energy consumption and low emission.

\begin{tabular}{cccccc}
\hline Variable & PGDP & DCO2 & WTI & TEU & GDP \\
\hline PGDP & 1.000000 & 0.000000 & $0.066574^{*}$ & -0.089812 & 0.052105 \\
& & & $(0.0000)$ & $(0.1228)$ & $(0.1015)$ \\
DCO2 & 0.000000 & 1.000000 & $-0.085126^{* * *}$ & $-1.258383 *$ & 0.164187 \\
& & & $(0.0711)$ & $(0.0000)$ & $(0.2194)$ \\
WTI & 0.000000 & 0.000000 & 1.000000 & 0.000000 & 0.000000 \\
TEU & 0.000000 & 0.000000 & $0.073686^{* *}$ & 1.000000 & $-0.221742^{* *}$ \\
& & & $(0.0428)$ & $(0.0297)$ \\
GDP & 0.000000 & 0.000000 & $-0.155857^{* *}$ & 0.000000 & 1.000000 \\
& \multicolumn{5}{c}{$(0.0173)$} \\
& \multicolumn{5}{c}{ Log likelihood: 232.6188} \\
\hline
\end{tabular}

Note: the value in brackets is $p$ value; * represents $1 \%$ significance level; ${ }^{* *}$ represents $5 \%$ significance level; and $* * *$ represents $10 \%$ significance level.

The estimated results show that: in the aspect of energy conservation, the influence coefficients in current period of international crude oil price, total energy consumption in China, and gross domestic product in China on energy consumption per GDP are 0.066574, -0.089812 , and 0.052105. Among them, the $p$ values of gross domestic product in China and total energy consumption are larger than 
0.1 , without statistical significance, and the $p$ value of international crude oil price is less than 0.5 , with statistical significance, which indicates that the influence of gross domestic product and total energy consumption in China on energy consumption per GDP is not significant in the short term in the status of low energy consumption and low emission. However, when we compared this with the status of high energy consumption, we saw that the influence of international oil price on energy use efficiency increases. In the aspect of pollutant emission, we observed carbon dioxide emissions compared to international crude oil prices, China's total energy consumption and China's GDP impact of the current coefficient of $-0.085126,-1.258383$ and 0.164187 . The $p$ value of gross domestic product in China is larger than 0.1 , without statistical significance, and $p$ values of international oil price and total energy consumption in China are higher than 0.05 , with statistical significance. Compared with the status of high emission, it is relatively weak. This indicates that economic development and environmental pollution in the short term is not directly affected, the influence of international oil price and energy consumption on energy emission is gradually weakened as well.

To sum up: the model estimation results show that, without classification of status, high energy consumption and high emission and low energy consumption and low emission in the short term are associated with a gradual reduction of energy consumption and emission. The total energy consumption in China has a positive impact on energy consumption per GDP and carbon dioxide emission in all three statuses, and only in the status of high energy consumption is the impact of gross domestic product in China on energy consumption per GDP and carbon dioxide emission positive. Moreover, at this time, the relations between international oil price and energy consumption and emission is negative. This indicates that the international oil price has certain inhibiting effects on energy conservation and emission reduction in China while energy consumption and economic development have certain improvement effects on energy conservation and emission reduction in China.

\subsubsection{Impulse Response Analysis of Energy Conservation and Emission Reduction in China to} International Oil Price

To analyze the long-term dynamic influence of international oil price on energy conservation and emission reduction in China, this paper respectively analyzed the impulse response of energy consumption per GDP and carbon dioxide emission compared to international oil price in three SVAR models within 25 years. We based this analysis on the model without classification of status, with high energy consumption and high emission, and with low energy consumption and low emission, (Figures 4-6).

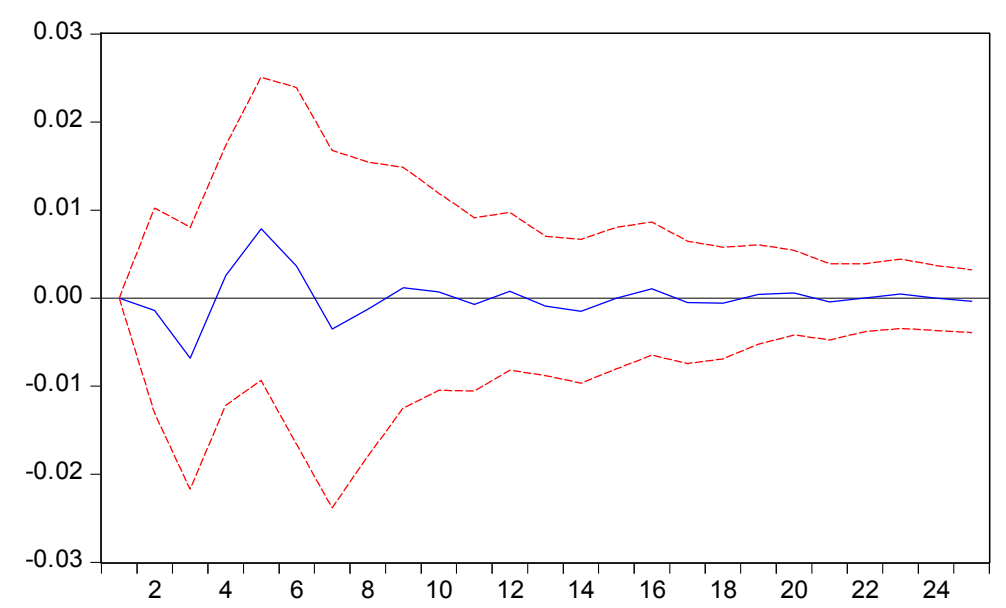

(a)

Figure 4. Cont. 


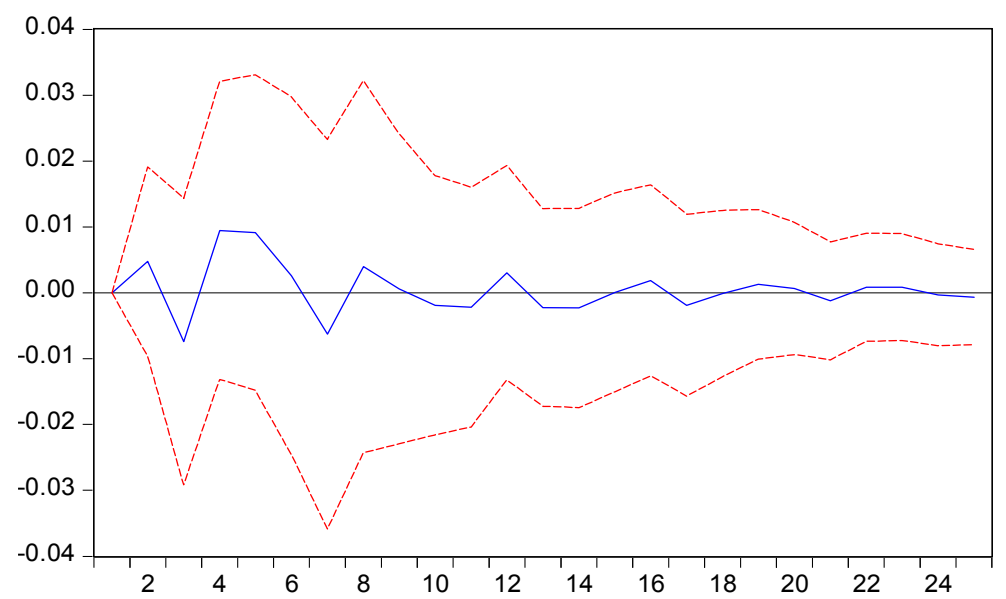

(b)

Figure 4. Impulse response of energy consumption per GDP (PGDP) (a) and carbon dioxide emission (DCO2) (b) to West Texas Intermediate (WTI) without the classification of status.

It can be observed from Figure 4 that the international crude oil price is relatively sensitive to the change of energy consumption per GDP. Due to the lag of energy conservation and emission reduction policy, the negative response amplitude of the impact of international crude oil price on energy consumption per GDP reaches the maximum in phase III, and the response value is 0.05 . However, in the next phase, it quickly reduces to the maximum negative response at -0.007 , and in the next phase, it quickly rises to the maximum with a response value of 0.008 . Then it starts to decline in phase VIII, and finally reaches a stable level at 0.04 . Affected by the lag of international crude oil price, the negative response of international crude oil price to carbon dioxide emission reaches the maximum in IV phase with response value 0.009 , the response value in phase VII and phase VIII are respectively -0.006 and 0.04 , and starts to attenuate in phase IX. In summary, the impact of international oil price on energy consumption per GDP and carbon dioxide emission is relatively significant in the short term rather than in the long term.

Figure 5 demonstrates the status of high energy consumption and high emission. Due to the excessively rapid energy consumption and the lag of energy conservation and emission reduction policy, the negative response amplitude of the international crude oil price on energy consumption per GDP reaches the maximum in phase III, and the response value is -0.007 , but it gradually diminishes in the each phase, and reaches the maximum negative response in phase VII (-0.0047). It starts to decline in phase IX and eventually maintains a response value of -0.0005 . On account of the large amount of energy emission, the positive response of international crude oil price to carbon dioxide emission reaches the maximum (0.11) when one phase is lagged, which is larger than the response value in the status without classification (0.009), but it rapidly decreases in the next phase, and reaches the maximum negative response in phase $\mathrm{V}(-0.013)$. The response value in phase VII is -0.011 , and starts to decline in phase IX. Compared with the status without classification, the impact of oil price on energy consumption per GDP and carbon dioxide is stronger in the short term, but weaker in the long term.

Figure 6 denotes the status in low energy consumption and low emission. Because the fluctuation of international oil price has an effect on enhancing energy use efficiency the international oil price is very sensitive to the change of energy consumption per GDP. In addition, as the effect of energy conservation and emission reduction policy is always lagged, the positive response amplitude of the impact of international crude oil price on energy consumption per GDP reaches its maximum in stage II with the response value 0.0022 . When compared with the status without classification and the status of high energy consumption and high emission, the response period stays the same for a longer 
period of time; however, the response value reduces to -0.0064 rapidly in the next phase. It starts damping in phase IX, and the response value is -0.0005 . The shocks of international crude oil price on carbon dioxide emission is weaker, and reaches the maximum positive response (0.019) in phase II. However, the influence in one phase lag is negative and reaches the maximum in phase III with the response value of -0.025 . The impact starts to decline in phase VIII where the response value is -0.004 . Compared with the status without classification and the status of high energy consumption and high emission, the impact of international oil price on carbon dioxide is stronger, and declines more rapidly, but the impact on energy consumption per GDP emission is weaker.

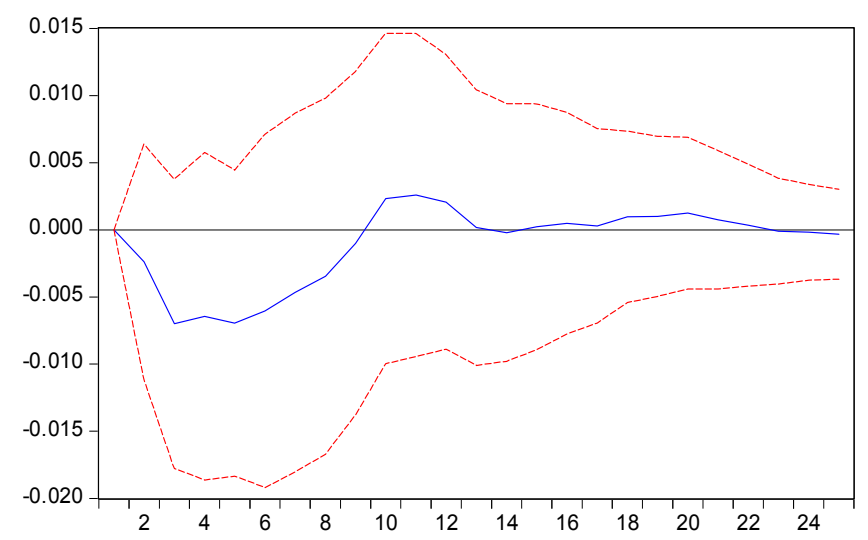

(a)

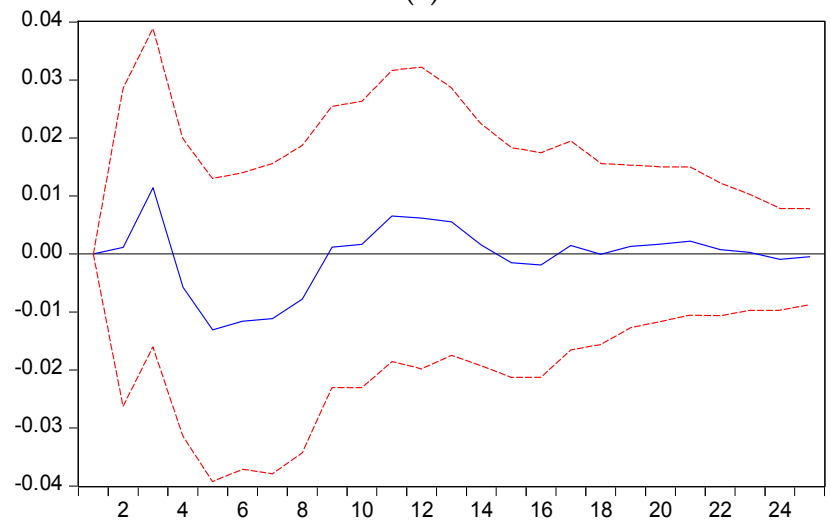

(b)

Figure 5. Impulse response of PGDP (a) and DCO2 (b) to WTI in the status of high energy consumption and high emission.

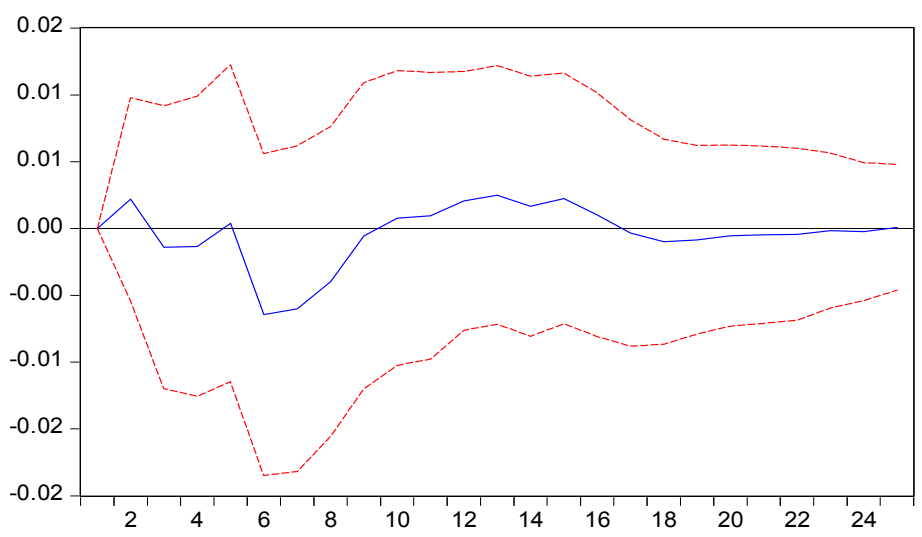

(a)

Figure 6. Cont. 


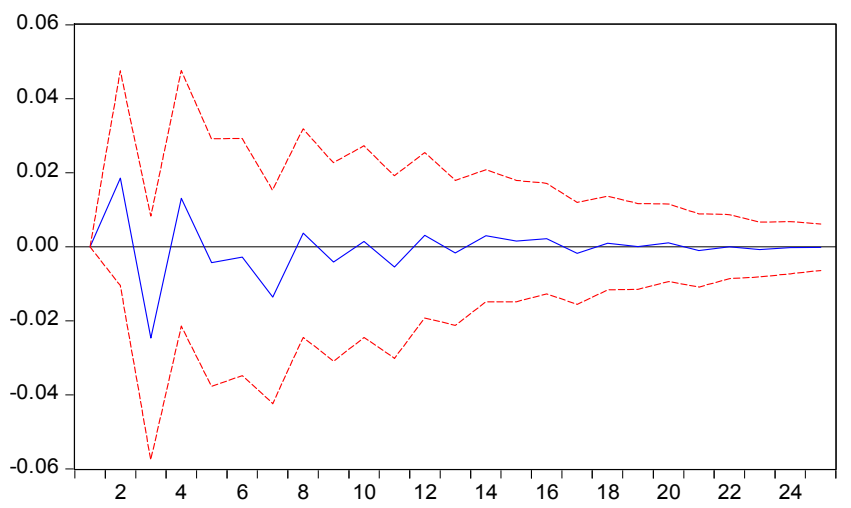

(b)

Figure 6. Impulse response of PGDP (a) and DCO2 (b) to WTI in the status of low energy consumption and low emission.

\section{Conclusions}

Based on the path analysis of international oil price on energy conservation and emission reduction and the SVAR model analysis, it can be concluded that, in the short term, the indirect influence of international oil price on energy consumption in China is relatively significant. Specifically, the influence of WTI crude oil on gross domestic product is 0.787 ; the elasticity of GDP in relation to total consumption of raw coal in China is 0.673 , the elasticity in relation to total consumption of crude oil in China is 0.870 , the elasticity in relation to total consumption of natural gas in China is 0.898 , and the elasticity in relation to total consumption of water and electricity in China is 0.979 . In the SVAR model analysis of international oil price on energy conservation and emission reduction in China, in the status without classification, the elasticity of international oil price to energy consumption per GDP and carbon dioxide emission is $9.22 \%$ and $5.02 \%$ respectively. In the status of high energy consumption and high emission, the elasticity of international oil price in relation to energy consumption per GDP and carbon dioxide emission is $4.31 \%$ and $6.51 \%$ respectively. In the status of low energy consumption and low emission, the elasticity of international oil price in relation to energy consumption per GDP and carbon dioxide emission is $6.66 \%$ and $-8.51 \%$ respectively. Oil price has become an important indirect influential factor on energy conservation and emission reduction in China.

Therefore, the main factors directly determining energy conservation and emission reduction in China are the situation of macroeconomic development as well as the energy consumption level. However, world economy and oil demand increase rapidly, so the indirect impact of international oil price in the long term cannot be ignored. In the status without classification, the impact of international oil price on energy conservation and emission reduction is larger than the impact of economic development and energy consumption on energy conservation and emission reduction. In addition, this paper also analyzes the factors that influence energy conservation and emission reduction in China in the status of high energy consumption and high emission and the status of low energy consumption and low emission to clarify that economic development may harm environment, but focusing on environmental protection also has a negative influence on energy consumption. Therefore, the research in this paper is of significance to the proposal of energy conservation and emission reduction policy in China during the 13th Five-Year Plan. This paper mainly analyses the international oil price in terms of energy conservation and emissions reduction in China. Further research would focus on the influence of primary energy such as coal or natural gas in terms of China's environmental impact.

Acknowledgments: This research is supported by the National Natural Science Foundation of China (NSFC) under grants No. 71473155, Postdoctoral Science Foundation special funds project of China No. 2014 T70130 and the Young Star of Science and Technology plan project of China's shaanxi province No. 2016KJXX-14. The authors would like to thank the anonymous referees as well as the editors. 
Author Contributions: All authors contributed equally to this work.

Conflicts of Interest: The authors declare no conflict of interest.

\section{References}

1. James, D.H. Macroeconomic Regimes and Regime Shifts. Available online: http://econweb.ucsd.edu/ jhamilto/handbook_regimes.pdf (accessed on 23 May 2016).

2. Hamilton, J.D. Oil and the macroeconomy since World War II. J. Polit. Econ. 1983, 91, 228-248. [CrossRef]

3. Kilian, L. Exogenous oil supply shocks: How big are they and how much do they matter for the U.S. economy? Rev. Econ. Stat. 2008, 90, 216-240. [CrossRef]

4. Hooker, M.A. What happened to the oil price-macroeconomy relationship? J. Monet. Econ. 1996, 38, $195-213$. [CrossRef]

5. Alvarez, L.; Hurtado, S.; Sanchez, I.; Thomas, C. The impact of oil price changes on Spanish and euro area consumer price inflation. Econ. Model. 2011, 28, 422-431. [CrossRef]

6. He, L.; Cheng, Y.; Fan, R.; Jin, L. Price Leverage Effect of Domestic Relative Energy Price on Carbon Emission. China Popul. Resour. Environ. 2015, 22, 1-11. (In Chinese) [CrossRef]

7. Liu, C. The Study of the Impact of Energy Price Changes on China Macroeconomy and Energy Conservation and Emissions Reduction. Math. Pract. Theory 2012, 42, 53-64. (In Chinese)

8. Chou, K.W.; Tseng, Y.H. Oil prices, exchange rate, and the price asymmetry in the Taiwanese retail gasoline market. Econ. Model. 2015, 10, 1-9. [CrossRef]

9. Jiang, J.; Marsh, T.L.; Tozer, P.R. Policy Induced Price Volatility Transmission: Linking the U.S. Crude Oil, Corn and Plastics Markets. Energy Econ. 2015, 10, 1-44. [CrossRef]

10. Donald, B.; Vance, G.; Tuttle, M.H. Retail and Wholesale Gasoline Price Adjustments in Response to Oil Price Changes. Energy Econ. 2015, 9, 1-20.

11. Huang, H.; An, H.; Gao, X. Identifying the multi scale impacts of crude oil price shocks on the stock market in China at the sector level. Phys. A: Stat. Mech. Appl. 2015, 434, 13-24. [CrossRef]

12. Lutz, K.; Robert, J.V. The Role of Oil Price Shocks in Causing U.S. Recession. Available online: http://www.federalreserve.gov/pubs/ifdp/2014/1114/ifdp1114.pdf (accessed on 23 May 2016).

13. Canova, F.; Pérez Forero, F.G. Estimating overidentied, non-recursive, time varying coeffcients structural VARs. Quantit. Econ. 2014, 5, 1-43.

14. Allegret, J.P.; Valérie, M. Audrey Sallenave. Oil price shocks and global imbalances: Lessons from a model with trade and financial interdependencies. Econ. Model. 2015, 49, 232-247. [CrossRef]

15. Wang, Y.; Liu, L.; Diao, X.; Wu, C. Forecasting the real prices of crude oil under economic and statistical constraints. Energy Econ. 2015, 51, 599-608. [CrossRef]

16. Chen, Q.; Xin, L. The extreme-value dependence between the crude oil price and Chinese stock markets. Int. Rev. Econ. Finance 2015, 39, 121-132. [CrossRef]

17. Petroleum \& Other Liquids. Available online: http://www.eia.gov/petroleum/ (accessed on 25 May 2016).

18. National Bureau of Statistics of China. Available online: http://data.stats.gov.cn/easyquery.htm? $\mathrm{cn}=\mathrm{C} 01$ (accessed on 25 May 2016).

19. iFind. Available online: http://www.51ifind.com/ (accessed on 25 May 2016).

20. Ibarra, C.A.; Blecker, R.A. Structural change, the real exchange rate and the balance of payments in Mexico, 1960-2012. Cambr. J. Econ. 2015, 2, 1-33. [CrossRef]

21. Feng, F. The Asymmetric Impact of International Crude Oil Price Shocks on China's PPI: An Empirical Analysis Based on Smooth Transition Model. Econ. Rev. 2013, 1, 71-77. (In Chinese)

22. Roger, B.; Yongmei, B. Explaining the price of oil 1971-2014: The need to use reliable data on oil discovery and to account for 'mid-point' peak. Energy Policy 2015, 86, 880-890.

23. Manojit, C.; Subrata, K.M. Exploring asymmetric behavior pattern from Indian oil products prices using NARDL and GHSOM approaches. Energy Policy 2015, 11, 262-272.

24. Debdatta, P.; Subrata, K.M. Asymmetric impact of crude price on oil product pricing in the United States: An application of multiple threshold nonlinear autoregressive distributed lag model. Econ. Model. 2015, 51, 436-443.

25. Ana, M.H.; Mohamad, B.K. The effects of oil price shocks on job reallocation. J. Econ. Dyn. Control 2015, 61, 95-113. 
26. Niaz, B.B.; Matteo, M. The role of outliers and oil price shocks on volatility of metal prices. Resour. Policy. 2015, 2, 139-150.

27. Wang, S.; Liang, D.; Wei, W.; Wang, D. Relationship Between Soil Physico-chemical Properties and Selenium Species Based on Path Analysis. Acta Pedol. Sinica 2011, 48, 823-830. (In Chinese)

(c) 2016 by the authors; licensee MDPI, Basel, Switzerland. This article is an open access article distributed under the terms and conditions of the Creative Commons Attribution (CC-BY) license (http://creativecommons.org/licenses/by/4.0/). 